\title{
Cost savings with transcutaneous screening versus total serum bilirubin measurement for newborn jaundice in hospital and community settings: a cost-minimization analysis
}

\author{
Stephanie McClean BSc(Nutr) MPH, Krista Baerg BSN MD, Julie Smith-Fehr MN, Michael Szafron PhD
}

\section{Abstract}

Background: Leading authorities in North America recommend universal screening via total serum bilirubin (TSB) measurement or transcutaneous bilirubinometry (TcB) for kernicterus prevention. We assessed costs associated with these 2 screening methods in hospital and in urban and rural community settings.

Methods: Our tertiary care centre in Saskatoon, with about 5600 births per year, serves the local population of 300000 ; in addition, $30 \%$ of patients are referred from outside the local community and surrounding area. We obtained health administrative data for two 6-month periods: before (June 1 to Nov. 30, 2015 [TSB program]) and after (June 1 to Nov. 30, 2016 [TcB-TSB program]) implementation of universal screening with TcB. Data on nurses' time and mileage were collected to assess the mean time for screening and sample transportation. We performed a cost-minimization analysis.

Results: The observed requirement for TSB blood draws decreased by $71.4 \%$ after implementation of TcB (1383.2/1000 live births to $397.8 / 1000$ live births), whereas the overall number of screens increased from 1383.2 to $2758.6 / 1000$ live births. The mean time per screen decreased from 12.52 (95\% confidence interval [Cl] 10.44-14.59) minutes with TSB to 2.94 (95\% Cl 2.55-3.33) minutes with TcB $(p<0.001)$. The estimated cost per TcB screen in hospital and community (urban and rural) settings was $\$ 3.54$ and $\$ 3.76$, respectively, and the estimated cost per TSB screen in hospital and in urban and rural community settings was $\$ 15.82, \$ 50.21$ and $\$ 65.03$, respectively. The estimated overall 6-month savings with the TcB-TSB hospital and community programs were $\$ 19760$ and $\$ 6417$, respectively.

Interpretation: The TcB-TSB program reduced nurses' time to screen and provided immediate results at the point of care. Transcutaneous bilirubinometry reduced the requirement for painful heel pokes while improving access to screening and decreasing the overall program cost.

$\mathrm{H}$ yperbilirubinemia causes jaundice, a yellowing of the skin and sclera ${ }^{1}$ that affects about $60 \%$ of term and $80 \%$ of preterm newborns. ${ }^{2}$ Around $2 \%$ of affected babies are at risk for severe neonatal hyperbilirubinemia (serum bilirubin level $>19.9 \mathrm{mg} / \mathrm{dL}[340 \mu \mathrm{mol} / \mathrm{L}]$ ), ${ }^{3}$ a risk factor for kernicterus. Kernicterus is a preventable cause of death and long-term disability. In North American and European countries, the incidence of kernicterus varies from 0.44 to 2.7 cases per 100000 live births. ${ }^{4-9}$ The economic burden of kernicterus on the Canadian health care system is estimated at \$1.3 million (2008). ${ }^{10}$ However, insurance claim settlements have been as high as $\$ 8$ million. ${ }^{11}$ In 2016 , failure to identify hyperbilirubinemia ranked as the 13 thriskiest practice in acute care. ${ }^{11}$ Leading North American authorities recommend universal bilirubin screening with transcutaneous bilirubinometry $(\mathrm{TcB})$ or measurement of total serum bilirubin (TSB) before hospital discharge. ${ }^{3,12}$ Although TSB is the current clinical standard, the required blood draw is painful. ${ }^{13,14}$ Transcutaneous bilirubinometry is a safe, noninvasive screening method that is available at

Competing interests: None declared.

This article has been peer reviewed.

Correspondence to: Krista Baerg, dr.kbaerg@usask.ca

CMAJ Open 2018. DOI:10.9778/cmajo.20170158 
point of care. ${ }^{15-18}$ Newer devices have been shown to be effective regardless of skin colour ${ }^{19-21}$ but are not approved for use with phototherapy ${ }^{22}$ and may provide less reliable results at extreme values. ${ }^{17,18,23,24}$ Transcutaneous bilirubinometry hour-specific nomograms, adjusted for increased sensitivity and created among local populations, are increasingly being developed and used. . $^{18,25,26}$

Economic impact studies have shown the cost-effectiveness of universal screening with TSB or TcB compared to clinical follow-up and testing driven by visual assessment. ${ }^{10,27-29}$ In 2 studies, the investigators compared the cost of TSB-based versus TcB-based universal screening, with mixed results. When TSB was shown to be more cost-effective, expensive disposable tips were required for $\mathrm{TcB}$, and staff time saved was not assessed. ${ }^{30,31}$ Our literature review revealed no comprehensive economic analysis comparing costs of screening using TSB and TcB that did not require disposable tips. The aim of the current study was to compare the costs associated with 2 jaundice screening methods, universal TSB screening (TSB program) and TSB referred by universal TcB screening (TcB-TSB program), used by a regional screening program for newborn jaundice. Costs were assessed in hospital as well as in urban and rural community settings.

\section{Methods}

Our tertiary care centre, with about 5600 births per year, serves the local population of $300000,83 \%$ of whom are of European ancestry. ${ }^{32}$ In addition, $30 \%$ of patients are referred from outside the local community and surrounding area. Universal screening for newborn jaundice is coordinated with newborn metabolic screening at 24-48 hours of age. ${ }^{3,33} \mathrm{~A}$ community follow-up program staffed by registered nurses follows newborns within 24-48 hours of discharge and subsequently for up to 14 days, as clinically indicated. Permanent full- and part-time staff are required to have the International Board Certified Lactation Consultant credential. When blood is drawn at a home visit, it is driven to the laboratory by the nurse. To expedite care and ensure sample integrity, trips to the laboratory are not batched. Metabolic screening in Saskatchewan is advised between 24 and 48 hours of age. Our unit policy is to do it after 24 hours. In 2015, newborns of 35 or more weeks' gestation received universal TSB screening coordinated with the newborn metabolic screen after 24 hours of age; ${ }^{33}$ timing of clinical follow-up was based on Canadian guidelines, ${ }^{3}$ and repeat TSB testing was done based on clinical assessment including visual inspection. In 2016, point-of-care screening with 5 JM-103 and 9 JM-105 (Dräger) TcB meters was integrated into the hospital and community screening protocols. All newborns of 35 or more weeks' gestation received $\mathrm{TcB}$ screening before the newborn metabolic screen. In addition, $\mathrm{TcB}$ screening was integrated into daily care and was performed daily in hospital, within 4 hours before hospital discharge and at each community follow-up visit. Transcutaneous bilirubinometry readings higher than the 95th lower predictive interval computed with the use of local data were confirmed with measurement of TSB..$^{3,22}$
We performed a cost-minimization analysis because both $\mathrm{TcB}$ and TSB are approved screening methods for newborn jaundice. We compared readmission rates for newborns with a most responsible diagnosis of neonatal jaundice within 12 weeks of birth, premature birth rates, average length of stay, number of community follow-up visits, and the number of TSB and TcB measurements across 2 time periods: before implementation of universal screening with TcB (June 1 to Nov. 30, 2015, time period 1) and after implementation of universal screening with TcB (June 1 to Nov. 30, 2016, time period 2).

\section{Data sources}

We obtained cross-sectional data for the 2 study periods. For both periods, we used organizational health data sets to obtain the number of live births, discharges and premature births, length of stay and total number of TSB specimens collected. Data for time and mileage analyses were collected throughout time period 2 .

\section{Time and mileage analyses}

We identified 2 separate times for measuring TSB: 1) TSB measurement coordinated with the newborn metabolic screen and 2) TSB measurement only. The time for obtaining a sample for TSB measurement with the newborn metabolic screen included only the nurse's time to draw the sample and graph/ interpret the result. In contrast, the time for TSB measurement included only the nurse's time to prepare for the blood draw, warm the newborn's heel, collect/send the sample to the laboratory and graph/interpret the result. The time to carry out TcB included the nurse's time to take the measurement and graph/interpret the result. Nurses in hospital and community settings collected these data. During time period 2, nurses in the community also collected data regarding their home visit mileage, mileage to travel to the laboratory from the home visit, and walking time to transport the sample from the car to the laboratory. We estimated travel time assuming urban travel speeds of $50 \mathrm{~km} /$ hour and rural travel speeds of $100 \mathrm{~km} /$ hour. The average excess mileage that resulted from transporting samples drawn in urban and rural community settings to the laboratory is the difference between the average mileage to travel from home visit to laboratory to home visit, and the average home visit mileage in each community setting (Figure 1).

\section{Cost estimation}

Costs of blood draws for TSB measurement included nurses' driving times, walking times and mileage related to sample transportation, the time to perform the screens and laboratory charges. Since $\mathrm{TcB}$ is done at point of care, costs for the TcB included only the nurses' times to perform the screens. Capital costs and calibration for $\mathrm{TcB}$ equipment and the chemistry analyzer were not assessed. In our setting, public health and hospital nurses are paid at differing rates, and we took this into consideration. Wages included hourly rates and benefits for 2016, and all costs were in 2016 Canadian dollars. 
Time period 1

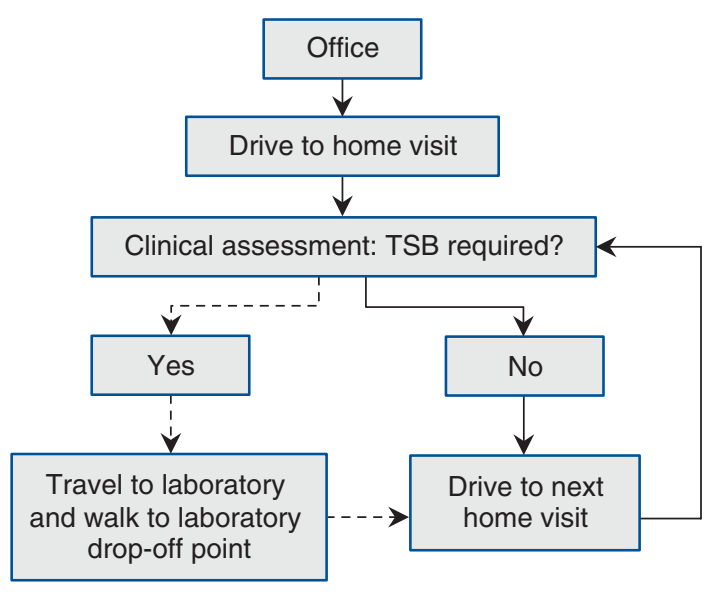

Time period 2

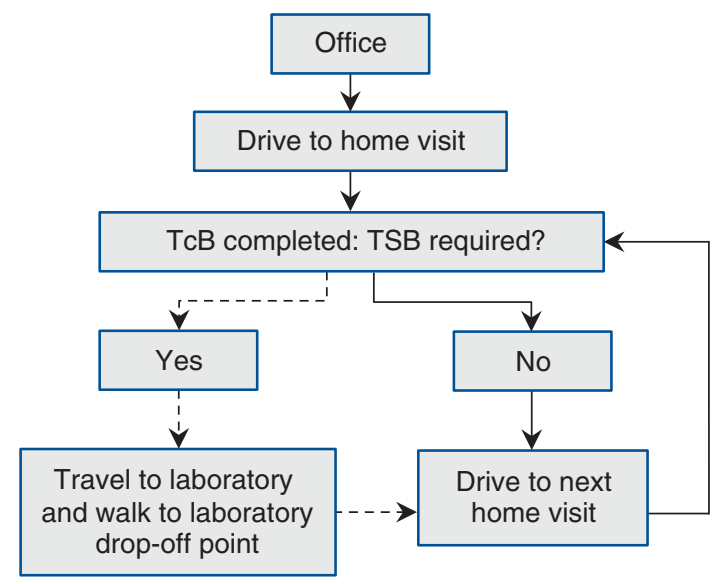

Figure 1: Flow diagram showing flow of work completed in community in the 2 time periods. Dashed lines depict the excess time/mileage between home visits required to transport a blood sample to the laboratory. Note: $\mathrm{TcB}=$ transcutaneous bilirubinometry, TSB $=$ total serum bilirubin.

\section{Statistical analysis}

We analyzed the data using SAS 9.4 (SAS Institute) and Microsoft Excel 2013. We computed means and 95\% confidence intervals (CIs) for time and mileage. If a sample size was less than 30, we assessed normality using the Shapiro-Wilk test (all relevant $p$ values $>0.05$ ). We performed $t$ tests for time and mileage analyses to identify significant differences between samples. We used Z-tests for the difference in 2 proportions to identify statistical differences between group characteristics and outcomes, including proportion of premature infants and readmission rates. All tests were 2-tailed, with $p<$ 0.05 defining statistical significance.

\section{Ethics approval}

The University of Saskatchewan Biomedical Research Ethics Board reviewed this study and determined that it was program evaluation/quality improvement and thus exempt from the requirement for board approval to proceed. Organizational approval was received.

\section{Resullts}

The live birth rate during time periods 1 and 2 was 2779 and 2763 , respectively. The corresponding numbers of postpartum unit discharges were 2466 and 2493 . There was no significant difference in the number of preterm births between the 2 periods (281 and 275 , respectively) $(p=0.8)$. Observed visits in the community follow-up program were similar across the 2 time periods, with 3399 in time period 1 and 3331 in time period 2. Observed lengths of hospital stay did not increase after the introduction of $\mathrm{TcB}$, with an average length of stay of 1.74 days in time period 1 and 1.70 days in time period 2 .
No significant difference in the number of newborns readmitted for jaundice within 2 weeks of discharge was found, with 54 readmissions per 2466 newborns $(2.2 \%)$ in time period 1 and 58 readmissions per 2493 newborns $(2.3 \%)$ in time period $2(p=0.8)$. Likewise, no significant differences were found in readmission rate by gestational age (Table 1). These results support the homogeneity of time periods 1 and 2 . Consequently, we assumed that the time and mileage data gathered in time period 2 would be indicative of the corresponding data for time period 1 .

\section{Screening measurements}

In time period 1, there were 3844 blood draws for TSB measurement. In time period 2, there were 1099 blood draws for TSB and $6523 \mathrm{TcB}$ screens (total of 2758.6 per 1000 live

\begin{tabular}{|c|c|c|}
\hline \multirow[b]{2}{*}{ Variable } & \multicolumn{2}{|c|}{ No. $(\%)$ of newborns } \\
\hline & $\begin{array}{c}\text { Time period } 1 \\
n=2466\end{array}$ & $\begin{array}{c}\text { Time period } 2 \\
n=2493\end{array}$ \\
\hline Readmitted & $54(2.2)$ & $58(2.3)$ \\
\hline 35-37 weeks' gestation & $\begin{array}{l}19(6.8) \\
n=281\end{array}$ & $\begin{array}{l}18(6.5) \\
n=275\end{array}$ \\
\hline$\geq 38$ weeks' gestation & $\begin{array}{c}35(1.6) \\
n=2185\end{array}$ & $\begin{array}{c}40(1.8) \\
n=2218\end{array}$ \\
\hline
\end{tabular}

*Time period 1: June 1 to Nov. 30, 2015; time period 2: June 1 to Nov. 30, 2016. †No significant difference was found between time periods in readmission of newborns for any age categories. 
births). Thus, although we observed a reduction of $71.4 \%$ in TSB blood draws, we observed an increase in the number of screens per 1000 live births (from 1383.2 to 2758.6). There were reductions of $75.3 \%$ and $49.3 \%$ in TSB blood draws in hospital and in the community, respectively (Table 2).

\section{Time and mileage analyses}

Table 3 summarizes the average times and mileage associated with the community follow-up program. Travel time estimates were found to be 5.5 and 12.0 minutes, respectively. The excess average mileage values for urban and rural TSB sample transportation were $4.58 \mathrm{~km}$ (95\% CI 3.23-5.94) and $20.04 \mathrm{~km}$ (95\% CI 8.37-31.72), respectively. The average nurse's time (regardless of location) for a lone blood draw for TSB measurement was significantly longer than for performing $\operatorname{TcB}(p<0.001)$.

\section{Cost estimation}

Cost estimates varied by method and location (Table 4). Most of the location variability was due to travel time, with nurse driving and walking times accounting for $52.3 \%$ of the total urban cost and $53.2 \%$ of the total rural cost.
Over the 6-month period, the estimated total savings with the TcB-TSB hospital and community programs were $\$ 19760$ and $\$ 6417$, respectively (Table 5), yet the total number of screens completed increased by $153 \%$ and $481 \%$, respectively. In hospital, the greatest savings were a reduction in cost due to a reduction in laboratory expenses $(74.7 \%$ of the cost reduction), followed by a decrease in nurses' time to screen $(25.3 \%$ ) (data not shown). In the community program, the largest savings were related to a reduction in travel time $(75.3 \%)$, followed by a reduction in laboratory expenses $(16.2 \%)$ and a decrease in mileage $(8.5 \%)$. In the community, the cost of the nurses' time to screen increased by $44.7 \%$ with the TcB-TSB program owing to policy that increased access to noninvasive screening at point of care.

\section{Interpretation}

In the current study, the estimated cost per $\mathrm{TcB}$ screen in hospital and community (urban and rural) settings was $\$ 3.54$ and $\$ 3.76$, respectively, whereas the cost per TSB screen was $\$ 15.82$ in hospital, and $\$ 50.21$ and $\$ 65.03$ in urban and rural community settings, respectively. We observed an overall

\begin{tabular}{|c|c|c|c|c|c|}
\hline \multirow[b]{2}{*}{ Location } & \multicolumn{2}{|c|}{ Time period 1, no. of samples } & \multicolumn{2}{|c|}{ Time period 2 , no. of samples } & \multirow[b]{2}{*}{$\%$ reduction } \\
\hline & Observed & Standardized* & Observed & Standardized* & \\
\hline Hospital & 3264 & 1174.5 & 805 & 291.3 & 75.3 \\
\hline Community & 580 & 208.7 & 294 & 106.4 & 49.3 \\
\hline Total & 3844 & 1383.2 & 1099 & 397.8 & 71.4 \\
\hline
\end{tabular}

\begin{tabular}{|c|c|c|c|c|}
\hline Variable & $\begin{array}{l}\text { No. of } \\
\text { cases }\end{array}$ & Mean $(95 \% \mathrm{Cl})$ & Median & Range \\
\hline \multicolumn{5}{|l|}{ Nurses' time, min } \\
\hline $\begin{array}{l}\text { Walk community sample from } \\
\text { car to hospital laboratory }\end{array}$ & 18 & $15.06(11.76-18.35)$ & 15.00 & $4.00-26.00$ \\
\hline Draw blood sample & 18 & $12.52(10.44-14.59)$ & 12.00 & $6.33-20.00$ \\
\hline $\begin{array}{l}\text { Perform transcutaneous } \\
\text { bilirubinometry }\end{array}$ & 56 & $2.94(2.55-3.33)$ & 2.33 & $0.33-7.00$ \\
\hline \multicolumn{5}{|l|}{ Mileage, km } \\
\hline \multicolumn{5}{|l|}{ Home visits } \\
\hline Urban & 524 & $8.36(7.91-8.81)$ & 7.00 & $1.00-25.00$ \\
\hline Rural & 110 & 33.95 (31.51-36.39) & 31.00 & $9.00-75.00$ \\
\hline \multicolumn{5}{|l|}{ Travel to laboratory } \\
\hline Urban & 127 & $6.47(5.83-7.12)$ & 6.00 & $1.00-18.00$ \\
\hline Rural & 14 & $27.00(20.70-33.30)$ & 27.00 & $3.00-53.00$ \\
\hline
\end{tabular}




\begin{tabular}{|c|c|c|c|c|c|c|}
\hline \multirow[b]{2}{*}{ Cost component } & \multicolumn{3}{|c|}{ Total serum bilirubin; cost, $\$$} & \multicolumn{3}{|c|}{ Transcutaneous bilirubinometry; cost, $\$$} \\
\hline & Urban & Rural & Hospital & Urban & Rural & Hospital \\
\hline Time to screen & 16.00 & 16.00 & 9.82 & 3.76 & 3.76 & 3.54 \\
\hline Travel time & 26.27 & 34.58 & - & - & - & - \\
\hline Mileage & 1.94 & 8.45 & - & - & - & - \\
\hline $\begin{array}{l}\text { Laboratory expenses } \\
\text { and disposables }{ }^{34}\end{array}$ & 6.00 & 6.00 & 6.00 & - & - & - \\
\hline Total & 50.21 & 65.03 & 15.82 & 3.76 & 3.76 & 3.54 \\
\hline \multicolumn{7}{|c|}{$\begin{array}{l}{ }^{*} \text { Costs are based on the per-minute combined salaries with benefits: } \$ 0.97615, \$ 1.27185 \text { and } \$ 1.27793 \text { for licensed practical nurses, } \\
\text { registered nurses in hospital settings and registered nurses in community settings, respectively. Table calculations are based on staffing } \\
\text { ratios for licensed practical nurses and registered nurses in hospital and in the community (Leanne Smith, Director, Maternal Services, } \\
\text { Saskatchewan Health Authority, Saskatoon: personal communication, 2018). }\end{array}$} \\
\hline
\end{tabular}

decrease of $71.4 \%$ in blood draws for TSB measurement with the introduction of $\mathrm{TcB}(75.3 \%$ in hospital and $49.3 \%$ in the community) despite improved access to screening of $153 \%$ in hospital and $481 \%$ in the community with TcB-TSB. The estimated total savings for the TcB-TSB hospital and community programs were $\$ 19760$ and $\$ 6417$, respectively, despite the improved access to screening. Assuming a 3-year lifespan for a TcB meter, the annual cost per meter would be about \$3600. Extrapolating the cost savings to 1 year (\$52 400), in our setting, a cost-neutral program would have 14 meters in circulation, equivalent to 1 meter per 390 births per year. In addition, patients received intangible benefits such as availability of point-of-care results and reduced exposure to painful heel pokes.

Our results align with findings by De Luca and colleagues, ${ }^{31}$ who estimated that, based on the positive predictive value of $\mathrm{TcB}$ with the BiliChek meter (Respironics), this device could safely avert $58 \%-79 \%$ of blood draws based on $\mathrm{TcB}$ thresholds of $10.0 \mathrm{mg} / \mathrm{dL}(171 \mu \mathrm{mol} / \mathrm{L})$ and greater than $12.0 \mathrm{mg} / \mathrm{dL}(205 \mu \mathrm{mol} / \mathrm{L})$. Other investigators have reported smaller reductions in TSB blood draws; however, they compared universal TcB screening to visual assessment, which led to fewer initial TSB measurements..$^{27,28,35,36}$ Overall program cost determination is affected by the threshold for TSB sampling. After implementation of $\mathrm{TcB}$ screening with a locally validated nomogram, our TSB rates were 291.3 and 106.4 per 1000 live births in hospital and the community, respectively. Other studies with the JM-103 device and specific unit protocols showed similar calculated rates, ranging from 101.8 to 141.6 per 1000 live births in hospital ${ }^{28,36}$ and the community. ${ }^{27}$

Our estimates of the cost of 1 TSB screen and $1 \mathrm{TcB}$ screen are similar to those in the literature, which range from $\mathrm{US} \$ 15^{17}$ to $£ 19.23$ (Can $\left.\$ 39.31\right)^{29}$ based on nursing time and laboratory expenses for TSB, and $£ 1.3$ (Can\$2.66) based on nursing time for TcB. ${ }^{29}$ The $\$ 26200$ in savings in our study equates to $\$ 1060$ in savings per 100 patients, similar to the figure of US\$1500 per 100 newborns reported by Srinivas and colleagues. ${ }^{17}$

\section{Limitations}

We used 2-week readmission rates for jaundice as a proxy to identify differences in health outcomes between screening methods since the incidence of kernicterus, peak bilirubin level and phototherapy time were not assessed. Furthermore, we were not able to distinguish infants of 35-37 weeks' gestational age from those of 38 weeks or more of gestational age. We estimated travel time from the mileage data, assuming standard rates of speed of $50 \mathrm{~km} / \mathrm{h}$ in urban areas and

Table 5: Costs associated with 6-month universal screening of total serum bilirubin and transcutaneous bilirubinometry, 2016 dollars

\begin{tabular}{|ccc|} 
& \multicolumn{2}{c|}{ Cost, \$ } \\
\cline { 2 - 3 } Setting; cost component & TSB program & $\begin{array}{c}\text { TcB-TSB } \\
\text { program }\end{array}$ \\
\hline Hospital & & \\
\hline Time to screen TSB & 32043 & 12155 \\
\hline Time to perform TcB & - & 14882 \\
\hline Laboratory expenses & 19584 & 4830 \\
\hline Subtotal & 51627 & 31867 \\
\hline Hospital cost savings & - & 19760 \\
\hline Community follow-up program & & 4703 \\
\hline Time to measure TSB & 9279 & 8727 \\
\hline Time to perform TcB & - & 924 \\
\hline Mileage & 1823 & 8174 \\
\hline Travel time & 16127 & 1764 \\
\hline Laboratory expenses & 3480 & 24292 \\
\hline Subtotal & 30709 & 6417 \\
\hline Community cost savings & - & 56159 \\
\hline Total cost & 82336 & 26177 \\
\hline Total savings & - & \\
\hline Note: TcB = transcutaneous bilirubinometry, TSB $=$ total serum bilirubin. \\
\hline
\end{tabular}


$100 \mathrm{~km} / \mathrm{h}$ in rural areas. This does not take into consideration traffic congestion or route and likely underestimated travel time and accompanying costs. Historical data provided the total number of TSB measurements completed in hospital and in the community. We assumed that, in time period 1 , every infant in hospital had 1 TSB blood draw concurrently with the newborn metabolic screen and that the remainder were follow-up TSB blood draws. We also assumed that, in time period 2, every TSB blood draw was a follow-up, both in hospital and in the community follow-up program. This likely led to an underestimate of cost savings of the TcB-TSB program, as the lone TSB blood draws took on average 5.8 minutes longer to take than the TSB blood draws obtained in conjunction with the metabolic screen, leading to a higher estimated cost for the TcB-TSB program. Owing to the nature of summary health data, we were unable to perform statistical analysis on the change in total TSB blood draws from time period 1 to time period 2, which limits the generalizability of our findings. However, our findings fall within those predicted by De Luca and colleagues, ${ }^{31}$ based on the positive predictive value of $\mathrm{TcB}$ with a similar $\mathrm{TcB}$ meter. We also could not statistically assess the difference in length of stay or number of community follow-up visits between time periods.

\section{Conclusion}

Transcutaneous bilirubinometry is noninvasive, reduced the requirement for blood draws by over $70 \%$ and improved access to screening. It reduced the nurses' time to screen and provided immediate results at the point of care. The infants in the 2 study periods had similar lengths of stay and readmission rates. With TcB screening, savings in hospital were related to reductions in nursing time and laboratory costs, whereas savings in the community program were related to reductions in travel time, laboratory costs and mileage. Over the 6-month period, the number of screenings doubled while the number of painful heel pokes decreased and the overall program cost decreased by $\$ 26177$. Further research is required to determine whether there is an ideal time to screen with $\mathrm{TcB}$ and whether screening at regular points of contact informs care, for example, whether additional screening results in earlier treatment of at-risk newborns or lower peak bilirubin levels.

\section{References}

1. Lauer BJ, Spector ND. Hyperbilirubinemia in the newborn. Pediatr Rev 2011; 32:341-9.

2. Sarici SU, Serdar MA, Korkmaz A, et al. Incidence, course, and prediction of hyperbilirubinemia in near-term and term newborns. Pediatrics 2004;113: 775-80.

3. Guidelines for detection, management and prevention of hyperbilirubinemia in term and late preterm newborn infants ( 35 or more weeks' gestation) - summary. Paediatr Child Health 2007;12:401-18.

4. Knapp AA, Metterville DR, Co JPT, et al. Evidence review: neonatal hyperbilirubinemia. Rockville (MD): Maternal and Child Health Bureau, Health Resources and Services Administration, US Department of Health and Human Services; 2012. Available: https://www.hrsa.gov/advisorycommittees/ mchbadvisory/heritabledisorders/nominatecondition/reviews/hyperbilirubinemia evidencerpt.pdf (accessed 2017 Feb. 2).

5. Burke BL, Robbins JM, Bird TM, et al. Trends in hospitalizations for neonatal jaundice and kernicterus in the United States, 1988-2005. Pediatrics 2009;123: 524-32.
6. Maimburg RD, Bech BH, Bjerre JV, et al. Obstetric outcome in Danish children with a validated diagnosis of kernicterus. Acta Obstet Gynecol Scand 2009; 88:1011-6.

7. Manning D, Todd P, Maxwell M, et al. Prospective surveillance study of severe hyperbilirubinaemia in the newborn in the UK and Ireland. Arch Dis Child Fetal Neonatal Ed 2007;92:F342-6.

8. Sgro M, Campbell DM, Kandasamy S, et al. Incidence of chronic bilirubin encephalopathy in Canada, 2007-2008. Pediatrics 2012;130:e886-90.

9. Ebbesen F. Recurrence of kernicterus in term and near-term infants in Denmark. Acta Paediatr 2000;89:1213-7.

10. Xie B, Da Silva O, Zaric G. Cost-effectiveness analysis of a system-based approach for managing neonatal jaundice and preventing kernicterus in Ontario. Paediatr Child Health 2012;17:11-6.

11. Risk reference sheet: perinatal — failure to identify/monitor byperbilirubinemia. Toronto: Health Insurance Reciprocal of Canada; 2012.

12. Risk reference sheet. Failure to identify/manage byperbilirubinemia. Toronto: Healthcare Insurance Reciprocal of Canada; 2016. Available: https://www. hiroc.com/getmedia/cb74e030-009e-482d-aeb5-2aee9891f852/13_Failure-to -Identify-Manage-Hyperbilirubinemia.pdf.aspx? ext=.pdf (accessed 2017 Feb. 2).

12. Maisels MJ, Bhutani VK, Bogen D, et al. Hyperbilirubinemia in the newborn infant $>$ or $=35$ weeks' gestation: an update with clarifications. Pediatrics 2009; 124:1193-8.

13. Anand KJS, Hickey PR. Pain and its effects in the human neonate and fetus. NEngl 7 Med 1987;317:1321-9.

14. Craig KD, Whitfield MF, Grunau RVE, et al. Pain in the preterm neonate: behavioural and physiological indices. Pain 1993;52:287-99.

15. Rubaltelli FF, Gourley GR, Loskamp N, et al. Transcutaneous bilirubin measurement: a multicenter evaluation of a new device. Pediatrics 2001;107: 1264-71.

16. Grohmann K, Roser M, Rolinski B, et al. Bilirubin measurement for neonates: comparison of 9 frequently used methods. Pediatrics 2006;117:1174-83.

17. Srinivas GL, Cuff CD, Ebeling MD, et al. Transcutaneous bilirubinometry is a reliably conservative method of assessing neonatal jaundice. 7 Matern Fetal Neonatal Med 2016;29:2635-9.

18. Yu ZB, Han S, Chen C. Bilirubin nomograms for identification of neonatal hyperbilirubinemia in healthy term and late-preterm infants: a systematic review and meta-analysis. World 7 Pediatr 2014;10:211-8.

19. Afanetti M, Eleni Dit Trolli S, Yousef N, et al. Transcutaneous bilirubinometry is not influenced by term or skin color in neonates. Early Hum Dev 2014;90: 417-20.

20. Samiee-Zafarghandy S, Feberova J, Williams K, et al. Influence of skin colour on diagnostic accuracy of the jaundice meter JM 103 in newborns. Arch Dis Child Fetal Neonatal Ed 2014;99:F480-4.

21. Raimondi F, Lama S, Landolfo F, et al. Measuring transcutaneous bilirubin: a comparative analysis of three devices on a multiracial population. BMC Pediatr 2012;12:70.

22. Instructions for use: JM-105. Lübeck (Germany): Dräger Medical Systems; 2014.

23. Mahram M, Oveisi S, Jaberi N. Trans-cutaneous bilirubinometery versus serum bilirubin in neonatal jaundice. Acta Med Iran 2015;53:764-9.

24. Taylor JA, Burgos AE, Flaherman V, et al. Discrepancies between transcutaneous and serum bilirubin measurements. Pediatrics 2015;135:224-31.

25. Romagnoli C, Tiberi E, Barone G, et al. Validation of transcutaneous bilirubin nomogram in identifying neonates not at risk of hyperbilirubinaemia: a prospective, observational, multicenter study. Early Hum Dev 2012;88:51-5.

26. Bental YA, Shiff Y, Dorsht N, et al. Bhutani-based nomograms for the prediction of significant hyperbilirubinaemia using transcutaneous measurements of bilirubin. Acta Paediatr 2009;98:1902-8.

27. Wainer S, Parmar SM, Allegro D, et al. Impact of a transcutaneous bilirubinometry program on resource utilization and severe hyperbilirubinemia. Pediatrics 2012;129:77-86.

28. Hartshorn D, Buckmaster A. 'Halving the heel pricks': evaluation of a neonatal jaundice protocol incorporating the use of a transcutaneous bilirubinometer. $f$ Paediatr Child Health 2010;46:595-9.

29. National Institute for Health and Clinical Excellence. Neonatal jaundice: costing report: implementing NICE guidelines. London (UK): National Health Service; 2010. Available: https://www.nice.org.uk/guidance/cg98/resources/costing -report-pdf-4729854349 (accessed 2017 Feb. 4).

30. Suresh GK, Clark RE. Cost-effectiveness of strategies that are intended to prevent kernicterus in newborn infants. Pediatrics 2004;114:917-24.

31. De Luca D, Zecca E, de Turris P, et al. Using BiliChek for preterm neonates in a sub-intensive unit: diagnostic usefulness and suitability. Early Hum Dev 2007;83:313-7.

32. Census profile. 2016 Census. Saskatoon, City [Census subdivision], Saskatchewan and Canada [Country] (table). Ottawa: Statistics Canada; 2017. Cat no 98-316 -X2016001. Available: www12.statcan.gc.ca/census-recensement/2016/dp-pd/ prof/index.cfm?Lang=E (accessed 2018 Mar. 24).

33. Newborn screening in Saskatchewan: information for bealth care providers. Regina (SK): Saskatchewan Ministry of Health; 2009.

34. Payment schedule for insured services provided by a physician. Government of Saskatchewan; 2016. Available: http://publications.gov.sk.ca/documents/13/ 31796-physician-payment-schedule-apr12-2016.pdf (accessed 2017 Feb. 18). 
35. Wickremasinghe AC, Karon BS, Saenger AK, et al. Effect of universal neonatal transcutaneous bilirubin screening on blood draws for bilirubin analysis and phototherapy usage. 7 Perinatol 2012;32:851-5.

36. Kaplan M, Shchors I, Algur N, et al. Visual screening versus transcutaneous bilirubinometry for predischarge jaundice assessment. Acta Paediatr 2008;97: 759-63.

Affiliations: School of Public Health (McClean, Szafron), University of Saskatchewan; Department of Pediatrics (Baerg), College of Medicine, University of Saskatchewan; Maternal Services (Smith-Fehr), Saskatchewan Health Authority - Saskatoon, Saskatoon, Sask.

Contributors: Julie Smith-Fehr and Krista Baerg conceived the study. Stephanie McClean collected and managed the data, and Stephanie
McClean and Michael Szafron analyzed the data. All of the authors contributed to the study design, interpretation of the data, drafting the manuscript and revising it critically for important intellectual content, gave final approval of the version to be published and agreed to be accountable for all aspects of the work.

Acknowledgements: The authors thank the Maternal Services staff on the Maternal Care Unit and Healthy \& Home, Saskatchewan Health Authority - Saskatoon for assistance with time and mileage data collection.

Supplemental information: For reviewer comments and the original submission of this manuscript, please see www.cmajopen.ca/content/6/3/ E285/suppl/DC1 